\title{
Increased plasma adrenomedullin levels in patients with acute myocardial infarction in proportion to the clinical severity
}

\author{
Yuji Miyao, Toshio Nishikimi, Yoichi Goto, Shunichi Miyazaki, Satoshi Daikoku, \\ Isao Morii, Takahiro Matsumoto, Shuichi Takishita, Atsuro Miyata, Hisayuki Matsuo, \\ Kenji Kangawa, Hiroshi Nonogi
}

Department of
Internal Medicine,
Division of Cardiology,
National
Cardiovascular
Centre, 5-7-1
Fujishirodai, Suita,
Osaka 565, Japan
Y Miyao
Y Goto
S Miyazaki
S Daikoku
I Morii
T Matsumoto
H Nonogi

Department of Internal Medicine, Division of Hypertension, National Cardiovascular Centre, 5-7-1 Fujishirodai, Suita, Osaka 565, Japan T Nishikimi

S Takishita

National

Cardiovascular Centre Research Institute, Suita, Osaka 565, Japan

A Miyata

K Kangawa

H Matsuo

Correspondence to: Dr Nishikimi, Department of Internal Medicine, Division of Hypertension and Nephrology, National Cardiovascular Centre, 5-7-1 Fujishirodai Suita, Osaka 565, Japan.

Accepted for publication 14 August 1997

\begin{abstract}
Objectives-To investigate the pathophysiological role of adrenomedullin in myocardial infarction.

Patients and design-Plasma concentrations of adrenomedullin, atrial natriuretic factor, and brain natriuretic peptide were measured by radioimmunoassay in 31 patients with acute myocardial infarction over four weeks, and in 44 normal subjects.

Results-In patients with acute myocardial infarction, plasma adrenomedullin reached a peak of (mean (SD) $14.0(9.0) \mathrm{pmol} / 1$ at 24 hours after the onset of symptoms and remained increased at all sampling points except the four week point compared with the value in normal subjects $(5.0(2.0) \mathrm{pmol} / \mathrm{l})$. Adrenomedullin concentrations on admission were higher in patients from Killip class II, III, and IV than class I, and correlated positively with peak plasma creatine kinase and left ventricular end diastolic volume index, and negatively with left ventricular ejection fraction. The values from 12 to 48 hours were negatively correlated with systemic vascular resistance index. During the time course studied, adrenomedullin concentrations were positively correlated with atrial natriuretic factor $(r=0.40, p<0.001)$ and brain natriuretic peptide $(r=0.53, \mathrm{p}<0.001)$. Conclusions-Plasma adrenomedullin concentrations increased in the acute phase of myocardial infarction in proportion with clinical severity, suggesting that adrenomedullin may play an important role in the pathophysiology of myocardial infarction.

(Heart 1998;79:39-44)
\end{abstract}

Keywords: adrenomedullin; acute myocardial infarction; natriuretic peptides

Adrenomedullin is a novel hypotensive peptide that was discovered in human phaeochromocytoma by monitoring its stimulating action on platelet adenosine $3^{\prime}, 5^{\prime}$-cyclic monophosphate (cAMP) production. ${ }^{1}$ The peptide consists of 52 amino acids with an intramolecular disulphide bond forming a ring structure of six residues, and shares slight homology with calcitonin gene related peptide and amylin. Like calcitonin gene related peptide, intravenous injection of adrenomedullin elicits a strong and long lasting hypotensive effect in anaesthetised rats. ${ }^{12}$ Immunoreactive adrenomedullin has been detected in human plasma, and human adrenomedullin messenger RNA has been reported to be highly expressed not only in phaeochromocytoma, but also in the normal adrenal medulla, kidney, lung, and cardiac ventricle. $^{34}$ Previous studies ${ }^{56}$ have reported that vascular smooth muscle cells possess specific adrenomedullin receptors that are functionally coupled to adenylate cyclase. It has also been shown that a nitric oxide/guanosine 3',5'-cyclic monophosphate (cGMP) mechanism may be involved in the regional vasculature. ${ }^{78}$ In addition, Nakamura et al ${ }^{9}$ reported that vasodilator potency of adrenomedullin was approximately $10-$ and 200 -fold more potent than sodium nitroprusside and acetylcholine when infused into the brachial artery in humans. These findings suggest that adrenomedullin may be involved in the physiological regulation of the circulation.

Several studies have shown that the plasma adrenomedullin concentration are increased in patients with heart failure, ${ }^{10}$ renal failure and hypertension. ${ }^{11}$ It is well known that plasma levels of atrial natriuretic factor and brain natriuretic peptide, which are vasodilator agents similar to adrenomedullin, are raised in patients with acute myocardial infarction. ${ }^{12}$ However, it is not fully understood how plasma adrenomedullin changes over time from the acute to the subacute phase in patients with acute myocardial infarction, or whether the concentrations are altered in relation to haemodynamic or clinical variables. The purpose of the present study was thus to determine the time course of changes in plasma adrenomedullin from the acute to the subacute phase and to investigate the relation between the plasma concentrations and haemodynamic and clinical variables in patients with acute myocardial infarction using our newly developed radioimmunoassay. ${ }^{3}$ We also investigated the relations between plasma adrenomedullin, atrial natriuretic factor and brain natriuretic peptide in these patients.

\section{Methods}

STUDY PATIENTS

Thirty one consecutive patients with acute myocardial infarction who were admitted within 12 hours after the onset of symptom were included in the study. The study patients consisted of 26 men and five women, ranging 
Table 1 Clinical characteristics of patients with acute myocardial infarction

\begin{tabular}{lr}
\hline Number of patients & 31 \\
Mean age (years (SD)) & $62.8(11.7)$ \\
Male sex, n (\%) & $26(83.9)$ \\
Disease history, n (\%) & \\
$\quad$ Hypertension & $17(54.8)$ \\
Angina pectoris & $23(74.2)$ \\
Previous myocardial infarction & $5(16.1)$ \\
Anterior myocardial infarction & $16(51.6)$ \\
Maximum level of CK (U/l, mean (SD)) & $3578(2589)$ \\
Forrester subset II, III, IV on admission, n (\%) & $9(31.0)$ \\
Killip class II, III, IV on admission, n (\%) & $8(25.8)$ \\
Time after onset to admission (h, mean (SD)) & $3.8(3.9)$ \\
Medication during protocol, n (\%) & $16(51.6)$ \\
$\quad$ Nitrates & $24(77.4)$ \\
Calcium channel antagonists & $9(29.0)$ \\
ACE inhibitors & \\
Treatment in acute phase, n (\%) & $22(71.0)$ \\
PTCR & $3(9.7)$ \\
Direct PTCA & \\
\hline ACE, angiotensin converting enzyme; CK, creatine kinase; \\
PTCR, percutaneous transluminal coronary recanalisation; \\
PTCA, percutaneous transluminal coronary angioplasty.
\end{tabular}

in age from 30 to 80 years, mean (SD) 62.8 (11.7) years. The diagnosis of acute myocardial infarction was made on the basis of chest pain persisting for at least 30 minutes, ST segment elevation of at least $0.1 \mathrm{mV}$ in at least two contiguous leads, and elevation of serum creatine kinase to more than twice the upper limit of the normal range. All patients were treated with aspirin and heparin after admission. Patients with renal failure (serum creatinine level $>226 \mathrm{~mol} / \mathrm{l}$ ) or severe inflammatory disease on admission were excluded. In three patients, intra-aortic balloon pumping was used for the treatment of cardiac failure immediately after admission. Forty four age and sex matched healthy subjects ( 28 men, 16 women; age range 50 to 69 years, mean 58.9 (5.8) years) served as the control group. Informed consent was obtained from each patient or their family on admission and from each patient after the general condition was stabilised. This study protocol was in agreement with the guidelines of the ethics committee of our institution.

BLOOD SAMPLING

In 25 of the 31 patients with acute myocardial infarction, blood samples were drawn immediately after admission, at $12,24,48$, and 72 hours after the onset of symptoms, and after one and four weeks, to determine the time course of changes in plasma adrenomedullin. In the remaining six patients, blood samples were only obtained immediately after admission because three of them had severe infection, two had coronary bypass surgery for residual ischaemia, and one died from cardiac pump failure. Blood sampling in patients from the third day through to the fourth week and in control subjects was done in the morning (0800 to 0900) in the supine position in a fasting state. Blood samples were taken from the antecubital or femoral vein and placed in tubes containing disodium ethylene diamine tetraacetic acid $(1 \mathrm{mg} / \mathrm{ml})$ and aprotinin $(500 \mathrm{U} /$ $\mathrm{ml})$. The plasma was immediately centrifuged at $4^{\circ} \mathrm{C}$ and stored at $-80^{\circ} \mathrm{C}$ until analysis.
ANGIOGRAPHY AND HAEMODYNAMIC MEASUREMENTS

In all of the 31 patients with acute myocardial infarction, coronary angiography was performed immediately after admission, and in 23 patients left ventriculography was also performed. Twenty two patients underwent intracoronary thrombolysis using tissue-type plasminogen activator, and 13 received rescue percutaneous transluminal coronary angioplasty because of the insufficient coronary flow (< TIMI flow grade III) after thrombolytic treatment. Three patients underwent primary percutaneous coronary angioplasty and the remaining six patients did not receive reperfusion treatment because the infarct related arteries were patent at the time of coronary angiography or because the admission was late (more than six hours after onset of symptoms). The occluded coronary arteries were recanalised successfully by these treatments in 29 patients. A Swan-Ganz catheter was inserted into the femoral vein after admission and was maintained there during the first two days. Haemodynamic variables, including heart rate, right atrial pressure, pulmonary artery pressure, pulmonary capillary wedge pressure, and cardiac index, were measured using this catheter. Cardiac index was measured by thermodilution in triplicate. Arterial pressure was measured with a brachial cuff. At four weeks after admission, coronary arteriography was performed in 29 patients and left ventriculography in 19. Left ventricular ejection fraction and left ventricular end diastolic volume index were calculated using the area/ length method.

\section{ASSAY FOR PLASMA ADRENOMEDULLIN}

CONCENTRATION

Radioimmunoassay for adrenomedullin was performed with adrenomedullin antibody (AM-M-Z), using a previously reported method. ${ }^{3}$ Half maximum inhibition of radioiodinated ligand binding by adrenomedullin was observed at $3.5 \mathrm{fmol} /$ tube; 0.5 to $32 \mathrm{fmol} /$ tube of adrenomedullin was measurable by this radioimmunoassay system. The intra-assay and interassay coefficients of variance were $5 \%$ and $8 \%$, respectively. The radioimmunoassay had $100 \%$ cross reactivity with the methionine sulphoxide form of adrenomedullin, but only $2 \%$ and $0.5 \%$ cross reactivity with adrenomedullin [13-52] and adrenomedullin [40-52], respectively. It had less than $0.01 \%$ cross reactivity with adrenomedullin [1-12] and adrenomedullin [13-31]. These data indicate that the antibody recognises the entire adrenomedullin molecule.

ASSAY FOR ATRIAL NATRIURETIC FACTOR AND BRAIN NATRIURETIC PEPTIDE

Radioimmunoassay was performed to measure plasma concentrations of atrial natriuretic factor and brain natriuretic peptide (Shiono RIA ANP and BNP assay kit, Shionogi Co, Osaka, Japan). Plasma concentrations of adrenomedullin, atrial natriuretic factor, and brain natriuretic peptide were measured in all control 

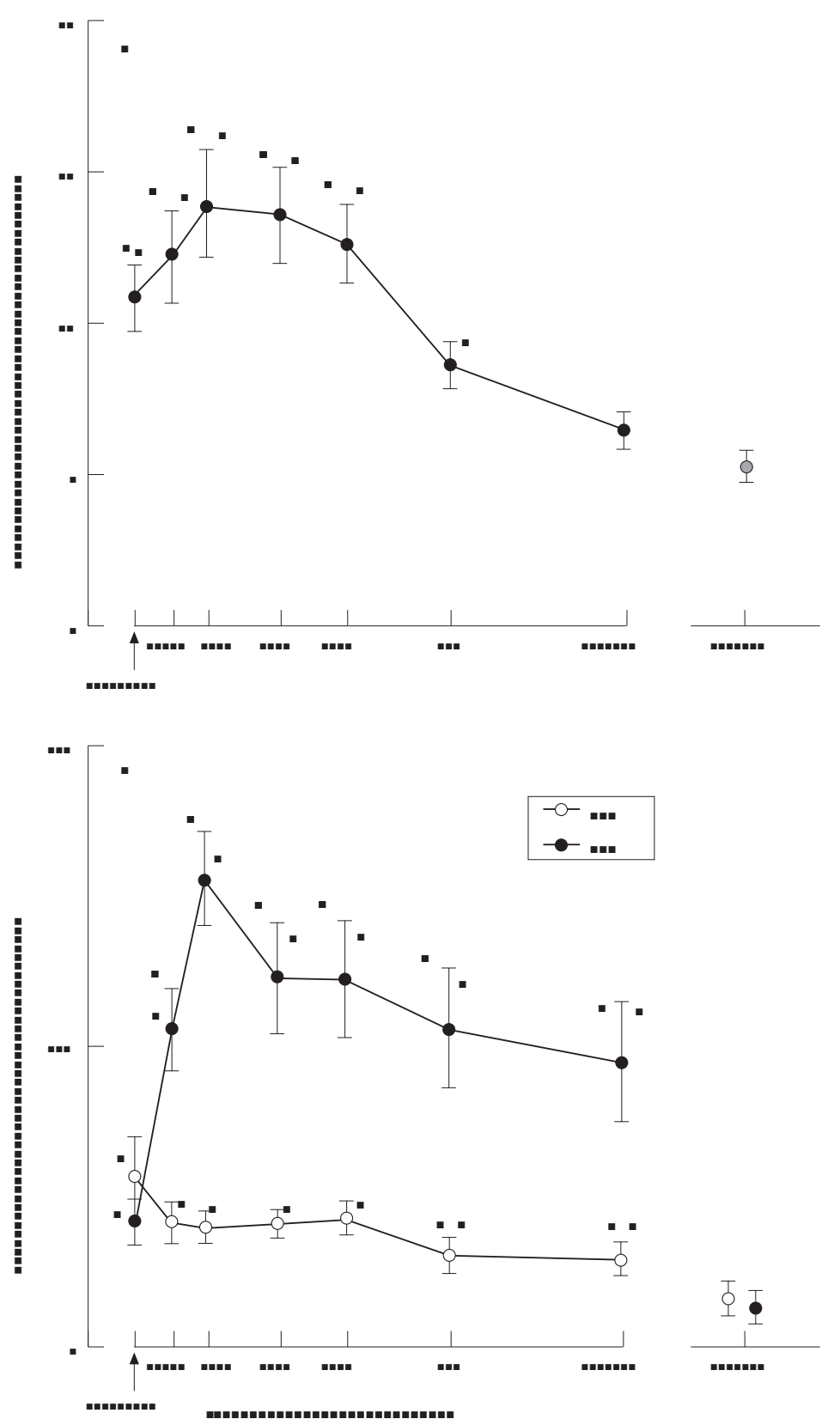

Figure 1 (A) Plots of plasma adrenomedullin in patients with acute myocardial infarction and in normal control subjects. Values are means, error bars $=S E M . \neq p<0.05, \neq \neq p<0.01 \mathrm{v}$ values at 4 weeks. (B) Plots of plasma atrial natriuretic factor $(A N F)$ and brain natriuretic peptide (BNP) in patients with acute myocardial infarction and in normal control subjects. Values are means, error bars $=S E M . t p<0.01 v$ values of $A N F$ on admission; $\int p<0.05$, $\int S p<0.01 v$ values of BNP on admission. ${ }^{\star} p<0.01 v$ control values.

subjects and in patients with acute myocardial infarction.

STATISTICAL ANALYSIS

Data are expressed as mean (SD) unless otherwise indicated. The plasma concentrations of adrenomedullin, atrial natriuretic factor, and brain natriuretic peptide were compared over the time course in patients with acute myocardial infarction using analysis of variance (ANOVA) for repeated measures. When the $\mathrm{F}$ value was found to be significant, the data were compared using Dunett's test. Correlations between plasma peptide concentrations and clinical variables were assessed by linear regression analysis. Variables between two groups were compared by unpaired Student's $t$ test or Mann-Whitney $U$ test. A p value $<0.05$ was considered statistically significant.

\section{Results}

BASELINE CHARACTERISTICS

Table 1 summarises clinical characteristics of study patients. Of the 31 patients with acute myocardial infarction, 24 had a history of angina pectoris, 18 had hypertension, and five had previous myocardial infarction. The average peak plasma concentration of creatine kinase was 3578 (2547) U/1. The time from the onset of symptoms to the first plasma sample on admission was 3.8 (3.9) hours, ranging from 0.5 to 12 hours. Of the 31 patients, only one died during the study protocol: he died on the second day from pump failure.

TIME COURSE OF CHANGES IN PLASMA ADRENOMEDULLIN, ATRIAL NATRIURETIC FACTOR, AND BRAIN NATRIURETIC PEPTIDE Of the 25 patients in whom serial blood samples were taken, 24 already had raised plasma adrenomedullin at the time of admission (10.9 (5.5) pmol/l) (fig 1A). The adrenomedullin concentrations thereafter increased further and reached a mean peak value of 14.0 (9.0) pmol/1 approximately 24 hours after the onset of acute myocardial infarction, remaining raised until seven days compared with the control value $(5.1(2.3) \mathrm{pmol} / \mathrm{l})$. Plasma adrenomedullin at 12 hours, 24 hours, 48 hours, and three days after the onset of acute myocardial infarction was significantly higher than the four week level. Twenty of the 31 patients with acute myocardial infarction were admitted within three hours from the onset of symptoms. Even in these patients, the mean plasma adrenomedullin on admission (12.1 (10.7) pmol/l) was already raised compared with the control group $(\mathrm{p}<0.01)$.

Figure 1B shows the time course of changes in plasma atrial natriuretic factor and brain natriuretic peptide from admission to the four week time point. Plasma atrial natriuretic factor had already reached a peak value of $56.2(63.5) \mathrm{pg} / \mathrm{ml}$ on admission, which was significantly higher than the seven day and the four week values $(p<0.01)$. Thereafter, the level decreased gradually. Plasma brain natriuretic peptide, which had already increased to $40.6(37.5) \mathrm{pg} / \mathrm{ml}$ on admission, increased further, reaching a peak of $155.4(79.0) \mathrm{pg} / \mathrm{ml}$ at 24 hours from the onset of symptoms. Thereafter, the level decreased gradually but was still higher at four weeks $(94.1(100.5) \mathrm{pg} /$ $\mathrm{ml})$ than on admission $(\mathrm{p}<0.05)$.

RELATION BETWEEN PLASMA ADRENOMEDULLIN AND INDICES OF PUMP FAILURE

Figure 2 compares plasma adrenomedullin in patients with acute myocardial infarction according to Killip classification (fig 2A) and Forrester's haemodynamic subset (fig 2B) on admission. Plasma adrenomedullin was significantly higher in patients in Killip classes II, III, and IV than in Killip class I (21.4 (14.9) pmol/ 1 v 10.9 (5.6) pmol/1, p < 0.05), and in Forrester subsets III and IV than in Forrester sub- 

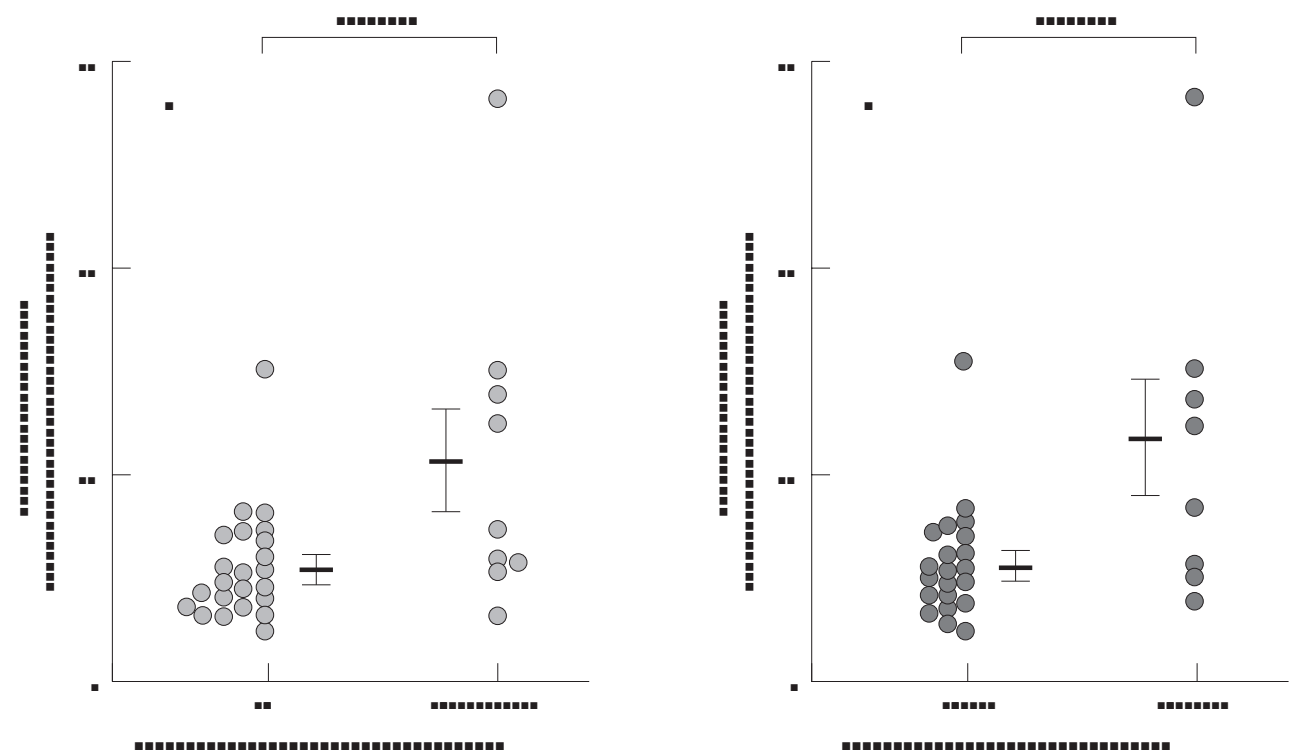

Figure 2 (A) Plasma adrenomedullin concentrations according to the Killip classification on admission in patients with acute myocardial infarction. Mean plasma adrenomedullin in Killip class II, III, and IV was significantly higher than in Killip class I. (B) Plasma adrenomedullin according to the Forrester subsets on admission in patients with acute myocardial infarction. Mean plasma adrenomedullin in Forrester subsets III and IV was significantly higher than in Forrester subsets I and II. Values are means (SEM).

sets I and II (22.9 (16.3) pmol/1 v $11.2(5.5) \mathrm{pmol} / \mathrm{l}, \mathrm{p}<0.05)$. Furthermore, the mean plasma adrenomedullin in patients who needed intravenous catecholamines or intraaortic balloon pumping for the treatment of cardiac failure was significantly higher than that in patients who did not need these treatments (18.7 (14.9) pmol/1 v 10.3 (4.6) pmol/1, $\mathrm{p}<0.05)$.

RELATIONS BETWEEN PLASMA ADRENOMEDULLIN, ATRIAL NATRIURETIC FACTOR, AND BRAIN NATRIURETIC PEPTIDE AND HAEMODYNAMIC VARIABLES

Plasma adrenomedullin concentrations were significantly correlated with atrial natriuretic factor $(r=0.46, \mathrm{p}<0.001)$ and brain natriuretic peptide $(r=0.59, \mathrm{p}<0.001)$ for all data points during the study period in patients with acute myocardial infarction.

Table 2 Correlation between plasma adrenomedullin and clinical variables on admission

\begin{tabular}{lcl}
\hline & Correlation coefficient $(r)$ & p value \\
\hline Peak CK & 0.49 & $<0.01$ \\
LVEDVI & 0.42 & $<0.05$ \\
LVEF & -0.54 & $<0.01$ \\
SVRI & -0.08 & NS \\
CI & -0.10 & NS \\
PCW & -0.05 & NS
\end{tabular}

CI, cardiac index; CK, creatine kinase; LVEDVI, left ventricular end diastolic volume index; LVEF, left ventricular ejection fraction; PCW, pulmonary capillary wedge pressure; SVRI, systemic vessel resistance index.

Table 3 Correlation between plasma adrenomedullin and time matched clinical variables from 12 hours to 48 hours

\begin{tabular}{lll}
\hline & Correlation coefficient $(r)$ & $p$ value \\
\hline SVRI & -0.37 & $<0.05$ \\
CI & 0.32 & NS \\
PCW & 0.03 & NS
\end{tabular}

CI, cardiac index; PCW, pulmonary capillary wedge pressure; SVRI, systemic vessel resistance index.
Table 2 shows the relations between plasma adrenomedullin concentrations and clinical variables on admission. Plasma adrenomedullin on admission was positively correlated with peak creatine kinase $(r=0.49, \mathrm{p}<0.01)$. The plasma concentrations were also correlated positively with left ventricular end diastolic volume index $(r=0.42, \mathrm{p}<0.05)$, but negatively with left ventricular ejection fraction $(r=-0.54, \mathrm{p}<0.01)$. There was no significant correlation between plasma adrenomedullin concentrations and pulmonary capillary wedge pressure, cardiac index, or systemic vascular resistance index on admission.

Table 3 shows the relations between the plasma adrenomedullin concentrations and the time matched values for pulmonary capillary wedge pressure, cardiac index, and systemic vascular resistance index, using all data obtained from 12 hours to 48 hours. There was no significant correlation between adrenomedullin and pulmonary capillary wedge pressure or cardiac index. However, plasma adrenomedullin concentrations from 12 hours to 48 hours were negatively correlated with the systemic vascular resistance index $(r=-0.37$, $\mathrm{p}<0.05)$. We also examined the relation between plasma atrial natriuretic factor and brain natriuretic peptide concentrations and haemodynamic variables. There was a significant correlation only between plasma brain natriuretic peptide and left ventricular end diastolic volume index on admission $(r=0.46$, $\mathrm{p}<0.05)$.

\section{Discussion}

Our study showed that in patients with acute myocardial infarction, (1) plasma adrenomedullin concentrations increase rapidly and reach a peak level at 24 hours after the onset of symptoms; (2) plasma concentrations on admission are higher in patients with pump 
failure and correlate positively with peak creatine kinase levels and left ventricular end diastolic volume index, but negatively with left ventricular ejection fraction; and (3) plasma concentrations correlate positively with atrial natriuretic factor and brain natriuretic peptide during the four week period after acute myocardial infarction.

THE MEANING OF RAISED ADRENOMEDULLIN Plasma adrenomedullin was shown to be increased in the very early phase of acute myocardial infarction (less than three hours from onset of symptoms), and to return to normal approximately four weeks later. Sugo et al have reported that the production and gene expression of adrenomedullin are markedly augmented by interleukin $1 \alpha$, interleukin $1 \beta$, tumour necrosis factor $\alpha$, tumour necrosis factor $\beta$, and lipopolysaccharide. ${ }^{13-15}$ Previous studies have also shown that the blood concentrations of inflammatory cytokines such as tumour necrosis factor $\alpha$, interleukin 6 , and interleukin 8 are markedly increased in patients with acute myocardial infarction in the acute phase. ${ }^{16-18}$ Multiple cytokines are capable of inducing acute phase proteins and multiple cell types may serve as sources of these cytokines. In addition, the plasma adrenomedullin concentrations correlated with indices of myocardial tissue damage or infarct size, such as peak creatine kinase, left ventricular ejection fraction, and left ventricular end diastolic volume index. Plasma adrenomedullin was also higher in patients with cardiac pump failure than in those without. Therefore, plasma adrenomedullinwhich may be stimulated by the several cytokines - is released as one of the acute phase reactants that appear in response to acute tissue injuries, including myocardial infarction. The concentrations found in patients with acute myocardial infarction may indirectly reflect the extent of ventricular dysfunction.

Plasma adrenomedullin values from 12 hours to 48 hours negatively correlated with the systemic vascular resistance index. Several studies have shown that adrenomedullin has a marked and prolonged systemic vasodilator activity. ${ }^{219}$ Recently, two studies have reported the effect of adrenomedullin infusions in man, ${ }^{20}$ but these reports gave contradictory results on the effect of adrenomedullin on systemic blood pressure. Given that the vascular smooth muscle cells and vascular endothelial cells synthesise and secrete adrenomedullin, ${ }^{13} 1422$ and that adrenomedullin specific receptors are present on the smooth muscle cells, ${ }^{56}$ the concentration of adrenomedullin around these cells is likely to be much higher than the basal plasma concentration. These data suggest that adrenomedullin may control vascular tone as a circulating hormone or as a paracrine factor.

ADRENOMEDULLIN $v$ ATRIAL AND BRAIN

NATRIURETIC PEPTIDES

In patients with acute myocardial infarction, the serial changes of adrenomedullin were for the most part similar to those of atrial natriuretic factor and brain natriuretic peptide; the plasma concentrations were increased in the acute phase and then gradually declined. Another similarity was that all these peptides were raised to a greater extent in patients with congestive heart failure (Killip class II, III, and IV). ${ }^{23-25}$ As a result, there were significant correlations between plasma adrenomedullin and atrial and brain natriuretic peptides in patients with acute myocardial infarction. Nishikimi et al have shown that plasma adrenomedullin is increased markedly in patients with chronic congestive heart failure, in proportion to its severity. ${ }^{10}$ In addition, Jougasaki et al reported that adrenomedullin immunoreactivity was markedly increased in the failing human ventricle. ${ }^{26}$ These data suggest that ventricular volume expansion is one of the stimuli for adrenomedullin in the heart failing because of acute myocardial infarction. Nevertheless, patients without heart failure (Killip class I) had higher plasma adrenomedullin values both on admission and at 24 hours than control subjects. This suggests that there are other mechanisms of increasing plasma adrenomedullin in addition to ventricular volume overload in patients with acute myocardial infarction.

One of the differences between adrenomedullin and natriuretic peptides was that adrenomedullin correlated with indices of the extent of myocardial tissue damage or infarct size, such as peak creatine kinase, left ventricular ejection fraction, and left ventricular end diastolic volume index. In addition, only plasma adrenomedullin concentrations were negatively correlated with the systemic vascular resistance index. These differences suggest that adrenomedullin may reflect the extent of myocardial tissue damage more accurately than natriuretic peptides.

ADRENOMEDULLIN IN HYPERTENSION

In our study, 18 of the 31 patients with acute myocardial infarction had a history of hypertension. Ishimitsu et al have reported that plasma concentrations of adrenomedullin are consistently higher in patients with chronic hypertension than in control subjects. ${ }^{11}$ In contrast, another study has shown that during a hypertensive attack, mean arterial pressure increases, with concomitant increases in plasma adrenaline and noradrenaline concentrations, whereas plasma adrenomedullin does not change. ${ }^{27}$ Furthermore, in the present study, even in patients without hypertension, the plasma adrenomedullin concentration on admission (10.9 (2.5) pmol/l) was significantly higher than the control value. Because our patients showed a typical "rapid rise and gradual fall" pattern of plasma adrenomedullin, the presence of chronic hypertension cannot explain our results.

STUDY LIMITATIONS

A relatively small number of patients were included in our study. In addition, we did not examine the influence of treatment on the serial changes in plasma adrenomedullin in individual patient. Success or failure of reperfusion and the use of vasodilator agents, 
catecholamines, or intra-aortic balloon pumping would influence the haemodynamics in the early phase of acute myocardial infarction. In relation to this, Kobayashi et $a l^{28}$ reported that plasma adrenomedullin concentrations were correlated with pulmonary capillary wedge pressure in the early stage of acute myocardial infarction, though this finding was not confirmed in the present study. Further studies are necessary to determine the influence of haemodynamics and treatment on plasma adrenomedullin and the clinical significance of this new peptide in patients with acute myocardial infarction.

CONCLUSIONS

In conclusion, plasma adrenomedullin is increased markedly in the early phase of acute myocardial infarction in proportion to clinical severity. Although the precise mechanisms by which adrenomedullin is synthesised and released remain to be elucidated, increased plasma adrenomedullin concentrations in patients with acute myocardial infarction may play an important role in its pathophysiology.

1 Kitamura K, Kangawa K, Kawamoto M, Ichiki Y, Nakamura S, Matsuo $\mathrm{H}$, et al. Adrenomedullin: a novel hypotensive peptide isolated from human pheochromocytoma. Biochem Biophys Res Commun 1993;192:553-60.

2 Ishiyama Y, Kitamura K, Ichiki Y, Nakamura S, Kida O Kangawa $\mathrm{K}$, et al. Hemodynamic effects of a novel hypotensive peptide, human adrenomedullin, in rats. Eur $\mathcal{f}$ Pharmacol 1993;241:271-3.

3 Kitamura K, Ichiki Y, Tanaka M, Kawamoto M, Emura J, Sakakibara S, et al. Immunoreactive adrenomedullin in human plasma. FEBS Lett 1994;341:288-90.

4 Kitamura K, Sakata J, Kangawa K, Kojima M, Matsuo H, Eto T. Cloning and characterization of cDNA encoding a precursor for human adrenomedullin. Biochem Biophys Res precursor for human adren

5 Eguchi S, Hirata Y, Kano H, Sato K, Watanabe Y, Watanabe $\mathrm{T}$, et al. Specific receptors for adrenomedullin in cultured 30 .

6 Ishizaka Y, Ishizaka Y, Tanaka M, Kitamura K, Kangawa K, Minamino N, et al. Adrenomedullin stimulates cyclic AMP formation in rat vascular smooth muscle cells. Biochem Bio phys Res Commun 1994;200:642-6.

7 Feng CJ, Kang B, Kaye AD, Kadowitz PJ, Nossaman BD. L-NAME modulates response to adrenomedullin in the hindquarters vascular bed of the rat. Life Sci 1994;55:4338.

8 Majid DSA, Kadowitz PJ, Coy DH, Navar LG. Renal response to intra-arterial administration of adrenomedullin in dogs. Am F Physiol 1996;270: F200-5.

9 Nakamura M, Yoshida H, Makita S, Arakawa N, Niinuma $\mathrm{H}$, Hiramori K. Potent and long-lasting vasodilatory effects of adrenomedullin in humans. Comparisons between normal subjects and patients with chronic heart failure. Circulation 1997;95:1214-21.
10 Nishikimi T, Saito Y, Kitamura K, Ishimitsu T, Eto T, Kangawa $\mathrm{K}$, et al. Increased plasma levels of adrenomedullin in gawa K, et al. Increased plasma levels of adrenomedullin in
patients with heart failure. $\mathcal{F}$ Am Coll Cardiol 1995;26: patients with $1424-31$.

11 Ishimitsu T, Nishikimi T, Saito Y, Kitamura K, Eto T, Kangawa $\mathrm{K}$, et al. Plasma levels of adrenomedullin, a newly dentified hypotensive peptide, in patients with hypertension and renal failure. $\mathcal{F}$ Clin Invest 1994;94:2158-61.

12 Morita E, Yasue H, Yoshimura M, Ogawa H, Jougasaki M, Matsumura $\mathrm{T}$, et al. Increased plasma levels of brain natriuretic peptide in patients with acute myocardial infarction. Circulation 1993;88:82-91.

13 Sugo S, Minamino N, Shoji H, Kangawa K, Kitamura K, Eto $\mathrm{T}$, et al. Production and secretion of adrenomedullin from vascular smooth muscle cells: augmented production by tumor necrosis factor- $\alpha$. Biochem Biophys Res Commun 1994;203:719-26.

14 Sugo S, Minamino N, Shoji H, Kangawa K, Kitamura K, Eto $\mathrm{T}$, et al. Interleukin-1, tumor necrosis factor and lipopolysaccharide additively stimulate production of adrenomedullin in vascular smooth muscle cells. Biochem Biophys Res Commun 1995;207:25-32.

15 Shoji H, Minamino N, Kangawa K, Matsuo H. Endotoxin markedly elevates plasma concentration and gene transcription of adrenomedullin in rat. Biochem Biophys Res Commun 1995;215:531-7.

16 Miyao $\mathrm{Y}$, Yasue $\mathrm{H}$, Ogawa $\mathrm{H}$, Misumi I, Masuda $\mathrm{T}$, Sakamoto $\mathrm{T}$, et al. Elevated plasma interleukin-6 levels in patients with acute myocardial infarction. Am Heart 7 1993;126:1299-304.

17 Neumann FJ, Ott I, Gawaz M, Richardt G, Holzapfel H, Jochum $\mathrm{M}$, et al. Cardiac release of cytokines and inflammatory responses in acute myocardial infarction. Circulation 1995;92:748-55.

18 Maury CPJ, Teppo AM. Circulating tumor necrosis factor- $\alpha$ cachectin) in myocardial infarction. F Intern Med 1989; 225:333-6.

19 Parkes DG. Cardiovascular actions of adrenomedullin in conscious sheep. Am Physiol Soc 1995;H2574-8.

20 Meeran K, O'Shea D, Upton PD, Small CJ, Ghatei MA, Byfield $\mathrm{PH}$, et al. Circulating adrenomedullin dose not regulate systemic blood pressure but increases plasma prolactin after intravenous infusion in humans: a pharmacokilactin after intravenous infusion in humans: a pharmaco

21 Lainchbury JG, Cooper GJS, Coy DH, Jiang N-Y, Lewis LK, Yandle TG, et al. Adrenomedullin: a hypotensive hormone in man. Clin Sci 1997;92:467-72.

22 Sugo S, Minamino N, Kangawa K, Miyamoto K, Kitamura $\mathrm{K}$, Sakata J, et al. Endothelial cells actively synthesize and secrete adrenomedullin. Biochem Biophys Res Commun 1994;201:1160-6.

23 Mukoyama M, Nakao K, Hosoda K, Suga S, Saito Y, Ogawa $\mathrm{Y}$, et al. Brain natriuretic peptide as a novel cardiac hormone in humans. F Clin Invest 1991;87:1402-12.

24 Yasue H, Yoshimura M, Sumida H, Kikuta K, Kugiyama K, Jougasaki $M$, et al. Localization and mechanism of secretion of B-type natriuretic peptide in comparison with secretion of B-type natriuretic peptide in comparison with those of A-type natriuretic peptide in normal subjects an

25 Wei CM, Heublein DM, Perrella MA, Lerman A, Rodeheffer RJ, McGregor CGA, et al. Natriuretic peptide system in human heart failure. Circulation 1993;88:1004-9.

26 Jougasaki M, Wei CM, McKinley LJ, Burnett JC. Elevation of circulating and ventricular adrenomedullin in human congestive heart failure. Circulation 1995;92:286-9.

27 Nishikimi T, Kitamura K, Saito Y, Shimada K, Ishimitsu T, Takamiya $\mathrm{M}$, et al. Clinical studies on the sites of production and clearance of circulating adrenomedullin in human subjects. Hypertension 1994;24:600-4.

28 Kobayashi K, Kitamura K, Hirayama N, Date H, Kashiwagi T, Ikushima I, et al. Increased plasma adrenomedullin in acute myocardial infarction. Am Heart f 1996;131:676-80. 